This item was submitted to Loughborough's Research Repository by the author.

Items in Figshare are protected by copyright, with all rights reserved, unless otherwise indicated.

\title{
Hybridising nitrogen doped titania with kaolinite: a feasible catalyst for a semi-continuous photo-degradation reactor system
}

\section{PLEASE CITE THE PUBLISHED VERSION}

http://dx.doi.org/10.1016/j.cej.2015.05.101

\section{PUBLISHER}

(C) Elsevier B.V.

\section{VERSION}

VoR (Version of Record)

\section{PUBLISHER STATEMENT}

This work is made available according to the conditions of the Creative Commons Attribution-NonCommercialNoDerivatives 4.0 International (CC BY-NC-ND 4.0) licence. Full details of this licence are available at: https://creativecommons.org/licenses/by-nc-nd/4.0/

\section{LICENCE}

CC BY-NC-ND 4.0

\section{REPOSITORY RECORD}

Sia, Tze H., Sheng Dai, Bo Jin, Mark J. Biggs, and Meng N. Chong. 2019. "Hybridising Nitrogen Doped Titania with Kaolinite: A Feasible Catalyst for a Semi-continuous Photo-degradation Reactor System”. figshare. https://hdl.handle.net/2134/18601. 


\title{
Hybridising Nitrogen Doped Titania with Kaolinite: a Feasible Catalyst for a Semi- Continuous Photo-Degradation Reactor System
}

Tze Haw Sia ${ }^{1}$, Sheng Dai* ${ }^{1}$, Bo Jin* ${ }^{1}$, Mark Biggs ${ }^{1}$ and Meng Nan Chong ${ }^{2}$

1. School of Chemical Engineering, The University of Adelaide, Adelaide SA 5005, Australia

2. School of Engineering, Monash University Malaysia Campus, Selangor Darul Ehsan, Malaysia.

Corresponding authors: Email: s.dai@adelaide.edu.au, Phone: +61 83131015

Email: bo.jin@adelaide.edu.au, Phone: +61 83137056

\begin{abstract}
The application of $\mathrm{TiO}_{2}$ catalyst for an industrial water treatment process is still limited due to its poor reusability, low oxidation efficiency and UV light use. Taking these challenges as the objective of this study, we integrated particle impregnation with nitrogen-doping methods to hybrid nitrogen doped $\mathrm{TiO}_{2}$ nanoparticles with kaolinite (NTK) as the photocatalyst for water treatment. SEM/TEM, XPS and XRD results revealed that the doped nitrogen in the NTK particle inclined toward interstitial, and the $\mathrm{TiO}_{2}$ nanocrystals were hybridized into the layered kaolinite minerals. Kaolinite was found to be an excellent $\mathrm{TiO}_{2}$ nanocatalyst supporter, providing promising adsorption transitions to not only sensitize $\mathrm{TiO}_{2}$ nanocrystals, but also enhance their photocatalytic oxidation capacity and recoverability. Kinetic studies showed that the NTK catalysts demonstrated a superior interfacial oxidation and photocatalytic degradation ability under visible light irradiation. Importantly, the NTK catalysts could be easily recovered for reuse with stable photo-degradation performance in a semi-continuous photoreactor process. The high degradation capacity, reusability and visible light accessibility of the NTK catalysts make the NTK-catalysed technology promising for industrial applications.
\end{abstract}

Keywords: Hybrid nanocatalysts; Titanium dioxide; Nitrogen doping; Photocatalytic degradation; Semi-continuous photoreactor. 


\section{Introduction}

$\mathrm{TiO}_{2}$ has been widely recognised as one of a few leading photocatalysts in semiconductor system for water treatment, due to its chemical stability, non-toxicity and advanced oxidation property [1]. The basic mechanism of $\mathrm{TiO}_{2}$ stimulated photocatalysis is the creation of an electron-hole pair by exciting an electron from valence band to conduction band through photon absorption. As $\mathrm{TiO}_{2}$ rutile and anatase have their band gaps of 3.1 and $3.2 \mathrm{eV}$, the photo-oxidation reaction using pure $\mathrm{TiO}_{2}$ could only be stimulated by UV, which is only a small fraction $(<4 \%)$ of solar spectrum[1, 2]. In recent decades, enormous researches have been given to the development of nano-sized and/or structured $\mathrm{TiO}_{2}$ as pioneering photocatalysts for water treatment. These $\mathrm{TiO}_{2}$ nanoparticles show large surface areas and diverse morphologies, which are beneficial for the photocatalysis. It is believed that the nanosized photocatalysts are able to demonstrate enhanced oxidation efficiency in a photoreactor [3]. However, the separation of these $\mathrm{TiO}_{2}$ nanoparticles from the photo-reactor system for reuse is an expensive practice, which makes the $\mathrm{TiO}_{2}$-based technology economically infeasible for an industrial application [1]. Therefore, their applications for the industrial processes are still facing a significant challenge due to the high operational costs for recovery or reuse of the $\mathrm{TiO}_{2}$ catalysts, and UV light use.

Recent studies have revealed that the incorporation of metallic or non-metallic elements, such as $\mathrm{Fe}, \mathrm{Cr}, \mathrm{N}, \mathrm{C}$ and $\mathrm{S}$ into $\mathrm{TiO}_{2}$ can effectively narrow the band gaps and makes the $\mathrm{TiO}_{2}$ catalyst access visible light as an energy source [3, 4]. Among those elements, nitrogen $(N)$ is a favoured doping element, as it contributes to the band gap narrowing by hybridizing its $p$ orbital with oxygen due to its similar size as oxygen and small ionization energy [4]. Commonly used techniques for the synthesis of the $\mathrm{N}$-doped $\mathrm{TiO}_{2}$ catalysts include ion implantation of $\mathrm{TiO}_{2}$ [5], calcination of $\mathrm{TiO}_{2}$ under nitrogen atmosphere at high temperature, and sol-gel method [6, 7]. To enhance the recovery ability of $\mathrm{TiO}_{2}$ catalysts, some studies 
have been conducted to immobilize or impregnate $\mathrm{TiO}_{2}$ particles into inert materials as the support carries such as clay [8,9], silica beads [5] and polymers [10]. These $\mathrm{TiO}_{2}$ immobilized hybrids can be synthesised by sol-gel $[9,11]$, electrochemical deposition or vapour deposition methods [12, 13]. Our group has synthesized a titania impregnated kaolinite $\left(\mathrm{TiO}_{2}-\mathrm{K}\right)$ catalyst, in which nanocrystallized $\mathrm{TiO}_{2}(\sim 10 \mathrm{~nm})$ were immobilized onto layered kaolinite (3.5 microns)[9, 14]. The $\mathrm{TiO}_{2}-\mathrm{K}$ catalysts demonstrated an enhanced photo-oxidation performance for organic degradation and bacterial disinfection, and promising recovery ability for reuse in a semi-conductor photocatalytic process.

It has been an on-going research practice to develop functional $\mathrm{TiO}_{2}$ catalysts, which has enhanced photo-oxidation capability and recovery ability, as well visible light accessibility, making the $\mathrm{TiO}_{2}$-catalysied technology economically beneficial for industrial applications [1, 14]. The question is whether it is possible to incorporate $\mathrm{N}$-doping and catalyst immobilization methods together to hybrid $\mathrm{N}$-doped $\mathrm{TiO}_{2}$ with functionalised carriers or supports [15]. We will synthesize a new composite photocatalyst of $\mathrm{N}$-doped $\mathrm{TiO}_{2}$ hybridized with kaolinite (NTK). A two-step synthesis approach in combination of particle impregnation and element doping was explored to incorporate nitrogen into $\mathrm{TiO}_{2}$ nano-crystals. As the carrier and supporter, natural kaolinite will be first chemically modified into porous and multiple layered structure, and then can be used as a platform for the immobilization and stabilization of the $\mathrm{N}$-doped $\mathrm{TiO}_{2}$. To our knowledge, this would be the first report of immobilization of nitrogen-doped titania onto a layer-structured kaolinite, leading to a hybrid NTK catalyst.

In this study, we will evaluate the photocatalytic oxidation kinetics, degradation capacity, visible light accessibility, recovery and reuse ability of the NTK catalysts in a laboratory photoreactor system operated as a batch and semicontinuous modes. It is expected that the 
NTK catalyst, photo-degradation kinetic data, and the photoreactor operation mode from this study could provide useful information for the development of photocatalytic processes for water and wastewater treatment.

\section{Experimental}

\subsection{Materials}

Physicochemical properties of kaolinite may be varied, depending upon the geographic source of origin. Natural dry-milled kaolinite obtained from the Unimin, Australia was used in this study. The kaolinite consists of $\mathrm{SiO}_{2}$ (48.7\%), $\mathrm{Al}_{2} \mathrm{O}_{3}$ (34.6\%), $\mathrm{TiO}_{2}$ (1.3\%), $\mathrm{Fe}_{2} \mathrm{O}_{3}$ (0.9\%) and trace amount of $\mathrm{K}_{2} \mathrm{O}, \mathrm{CaO}, \mathrm{MgO}$ and $\mathrm{Na}_{2} \mathrm{O}$. The detailed physical and chemical characteristics of this kaolinite were reported in our previous work [9].

Commercial $\mathrm{TiO}_{2}$ nanoparticles (P25, Degussa, Germany), composing of $80 \%$ anatase and $20 \%$ rutile were used as received. P25 has a surface area of $50 \pm 5 \mathrm{~m}^{2} \mathrm{~g}^{-1}$ and a particle size range of 25-85 nm. Kaolinite impregnated titania nano-crystallites $\left(\mathrm{TiO}_{2}-\mathrm{K}\right)$ was prepared according to our previous approach [9]. Both the $\mathrm{P} 25$ and $\mathrm{TiO}_{2}-\mathrm{K}$ were used as the references.

Considering its chemical structure, molecular weight and diazo bonds, Congo Red (CR) $\left(\mathrm{C}_{32} \mathrm{H}_{22} \mathrm{~N}_{6} \mathrm{Na}_{2} \mathrm{O}_{6} \mathrm{~S}_{2}\right.$, Colour Index 22120, Labchem Ajax Finechem, Australia) was used as a model toxic organic contaminant to simulate the industrial wastewater for the evaluation of photo-degradation performance of NTK catalysts in a photo-reactor system

\subsection{Synthesis of the NTK catalyst}

Natural kaolinite was pre-treated to enhance its surface availability prior to the subsequent heterocoagulation process with $\mathrm{TiO}_{2}$ sols [9]. $5 \mathrm{~g}$ kaolinite cream was soaked in $50 \mathrm{ml} 1 \mathrm{M}$ $\mathrm{HCl}$ for $24 \mathrm{~h}$ to obtain a slightly positively charged clay suspension. The suspension was filtered and washed thoroughly using Milli-Q water until no traceable chloride ion could be 
detected. The surface treated kaolinite was dried at $200{ }^{\circ} \mathrm{C}$ and stored. $20 \mathrm{ml}$ tetrabutyl orthotitanate (Fluka, $97 \%$ min assay) and $10 \mathrm{ml}$ triethylamine (Unilab, $99 \%$ min assay) were dissolved in $50 \mathrm{ml}$ absolute ethanol (Labserve, $99.5 \%$ min assay) and stirred for $30 \mathrm{~min}$ at room temperature. $30 \mathrm{ml}$ absolute ethanol and $10 \mathrm{ml}$ Milli-Q water were pre-mixed in another flask, and then added into the above solution drop-by-drop. The mixed system was continuously stirred at room temperature for $2 \mathrm{~h}$ until a transparent sol-gel was obtained. The synthesized sol-gel was drop-wisely added to a $10 \%$ aqueous suspension of pre-treated kaolinite and stirred at room temperature for another $2 \mathrm{~h}$. The obtained gel-clay mixture was allowed to settle for $16 \mathrm{~h}$ colloidation before it being dried at $70^{\circ} \mathrm{C}$, followed by calcination for $5 \mathrm{~h}$ at designed temperatures of $300,400,500$ and $600{ }^{\circ} \mathrm{C}$ to produce our NTK catalysts, as required for the studies.

\subsection{Characterisation of the NTK Catalysts}

The morphological and surface characteristics of the resultant NTK particles were analysed using an FEI Quanta 450 scanning electron microscope (SEM) (SEM, S-4800) equipped with Apollo XP SDD EDAX detector at an accelerating voltage of $10 \mathrm{kV}$. Thin platinum coating was applied on particle sample surface prior to analysis. TEM was performed on a Philips CM-100 TEM at an accelerating voltage of $100 \mathrm{kV}$. The NTK and $\mathrm{TiO}_{2}-\mathrm{K}$ particles were suspended in ethanol (ca. 0.01\% w/v), followed by ultrasonic treatment. The dispersion was dropped to a copper grid and dry in room temperature for TEM measurements.

Braunneur - Emmet - Teller (BET) specific surface area and pore size of the NTK catalysts were measured performed using a Micromeritics gas adsorption analyser (Gemini Type 2375) at $77 \pm 0.5 \mathrm{~K}$ in liquid nitrogen. Prior to the surface analysis, the sample loaded vessels were vacuum treated overnight at $105^{\circ} \mathrm{C}$ and evacuation pressure of 50 mTorr. Nitrogen sorption isotherms were analysed for the specific surface area using the BET equation. 
The crystal structure, phase identification and quantification of the synthesized NTK particles were analysed by an X-ray diffraction (XRD) analysis (XRD, Bruker AXS D8 Advance diffractions) using a Huber Guinier Image Plate G670 with $\mathrm{K}_{\alpha}$ radiation over an angular range of $5-90^{\circ}$. The XRD patterns were recorded on a Shimadzu LabX-600 diffractometer with $\mathrm{Cu} \mathrm{K}_{\alpha}$ radiation $(\lambda=0.1548 \mathrm{~nm})$. The size of the synthesised NTK particles was determined using Scherrer formula $L=K \lambda /(\beta \cos \theta)$, where $K$ is a constant of $0.89, \lambda$ is the wavelength characteristic of the $\mathrm{Cu} \mathrm{K}_{\alpha}$ radiation, $\beta$ is the full width at half maximum , and $\theta$ is the angle at which the (100) peak appears. The mass percent of anatase in the NTK and $\mathrm{TiO}_{2} / \mathrm{K}$ particles was calculated from equation:

$$
\left.X_{A}=\left[1+1.26\left(I_{R} / I_{A}\right)\right]\right)^{-1}
$$

where $X_{A}$ is the mass (\%) of anatase in the particles , and $I_{R}$ and $\mathrm{I}_{\mathrm{A}}$ were determined from the peak area of rutile (110) and anatase (101) diffraction peaks, respectively.

The surface chemical composition of the NTK samples was analysed by X-ray photoelectron spectroscopy (XPS) (Leybold LHS10 spectrometer) with $\mathrm{Al} \mathrm{Cu} \mathrm{K} \alpha$ radiation source. All the binding energies were referenced to the $\mathrm{C} 12$ peak at $284.5 \mathrm{eV}$ of surface adventitious carbon. Fourier transform infrared spectrum (FTIR) was measured using a Nicolet 6700 FTIR with attenuated total reflectance assembly and scanned from the wave-numbers of $650-4000 \mathrm{~cm}^{-1}$.

\subsection{Photocatalytic Activity and Degradation in Laboratory Photoreactor System}

Optical absorption characteristics of the NTK and $\mathrm{TiO}_{2}-\mathrm{K}$, and P25 photocatalyst particles were measured using a UV-vis. spectroscopy at 200 - $600 \mathrm{~nm}$. The photocatalytic degradation of these $\mathrm{TiO}_{2}$ catalysts was carried out in a self-designed $4 \mathrm{dm}^{3}$ annular slurry photoreactor (ASP) [14], as showed in Fig 1(I). The photo-reactor was equipped with a $8 \mathrm{~W}$ light lamp with a designed wavelength, feeding and sampling ports, $\mathrm{pH}$ and temperature sensors, and a water jacket for temperature control. The performance of respective $\mathrm{TiO}_{2}$ 
derivatives was evaluated across the CR photo-degradation. The starting CR concentration was $20 \mathrm{ppm}$, while the loading of photocatalyst was adjusted to $1 \mathrm{~g} \mathrm{dm}^{-3}$. Control trials were conducted using the $\mathrm{TiO}_{2}-\mathrm{K}$ catalyst and kaolinite particles under visible light irradiation, as well as the photoreactor system without $\mathrm{TiO}_{2}$ catalysts and kaolinite particles. To eliminate adsorption impact of the kaolinite particles on Congo red removal, all experiments were conducted under dark adsorption for 30 min prior to sampling to ensure photocatalyst particles could achieve equilibrium adsorption. The airflow rate of the reactor and other operational functionality were calibrated using the method reported by Chong et al.[14].

Photocatalytic oxidation performance of the NTK catalysts was evaluated using the ASP system operated as a batch mode. Studies on the degradation capacity and reusability of the NTK catalysts were carried out in a batch and semi-continuous operation mode using the ASP system. The semi-continuous mode was operated as a three phase cycle: wastewater recharge, photo-degradation reaction, and effluent discharge and catalyst reactivation, as sketched in Fig 1(II).

\subsection{Chemical and Data Analysis}

A monochromatic spectroscopy method using a Varian Cary 5000 UV-Vis spectrophotometer was used to measure the $\mathrm{CR}$ concentration at 496.5nm. The decolourisation and decomposition of Congo red were measured by detecting the absorbance at 496 and $300 \mathrm{~nm}$, respectively. All sampling and analysis were conducted in triplicates. All data were calculated from the average values of the triplicates. The results presented in the table and figures were provided with the deviation of $95 \%$ CI.

\section{Results and Discussion}

\subsection{Synthesis and Characterisation of the NTK Catalysts}


The NTK catalysts were synthesised by a modified two-step sol-gel method. The first step was to prepare the $\mathrm{N}$-doped $\mathrm{TiO}_{2}$ sol-gels, where triethylamine $\left(\mathrm{Et}_{3} \mathrm{~N}\right)$ was chosen as the nitrogen source due to the chelating effect of partially deprotonated $\mathrm{Et}_{3} \mathrm{~N}$ on titanium atoms. We used water and ethanol mixed solvent to induce the steric hindrance between precursors and water molecule. The NTK catalysts were synthesised by charging the above resulting Ndoped $\mathrm{TiO}_{2}$ sol-gels to the pre-treated kaolinite suspension. The slightly positive charged kaolinite was able to interact with the negatively charged $\mathrm{TiO}_{2}$ sol-gels through electrostatic interaction. The resultant NTK particles were subject to further calcination at 300, 400, 500, and $600{ }^{\circ} \mathrm{C}$ with their nomenclature referred as NTK300, NTK400, NTK500 and NTK600 catalysts in this study. For comparison purpose, the $\mathrm{TiO}_{2}-\mathrm{K}$ was also prepared according to similar approach with the previous study $[9,14]$, except for the nitrogen-doping process.

The morphological characteristics of the NTK particles are presented in Fig 2. Both SEM and HRTEM images show that the synthesized $\mathrm{TiO}_{2}$ crystals were comprised in a rocky texture rather than an even film covering kaolinite surface. The apparent size of spherical $\mathrm{TiO}_{2}$ particles was approximately $10 \mathrm{~nm}$. The low magnification SEM image shown in Fig 2c indicates that the layered structure of kaolinite remained in the synthesized NTK particles. The photo-oxidation capacity of a photocatalyst is strongly influenced by its particle size, morphology, crystalline phase, specific surface area, porosity and others. Our NTK particles consisted of layered structured kaolinite with rocky textured $\mathrm{TiO}_{2}$ nanocrystals either on the surface. Such layered structures can alter the surface properties of kaolinite particles. The incorporation of $\mathrm{TiO}_{2}$ nanocrystals on the kaolinite minerals results in a highly porous structure, which remarkably increases the specific surface area and porosity of the NTK catalysts. These were evidenced from the specific surface areas as determined using nitrogen sorption measurements. Our BET results show that the specific surface area increased from $35.6 \mathrm{~m}^{2} \mathrm{~g}^{-1}$ for natural kaolinite to $45.5 \mathrm{~m}^{2} \mathrm{~g}^{-1}$ (NTK300), $51.8 \mathrm{~m}^{2} \mathrm{~g}^{-1}$ (NTK400), $55.6 \mathrm{~m}^{2} \mathrm{~g}^{-1}$ 
(NTK500) and $48.7 \mathrm{~m}^{2} \mathrm{~g}^{-1}$ (NTK600). The pore sizes for the NTK catalysts varied in a range of 8.8 - 9.6nm when the NTK catalysts were prepared at $300-500{ }^{\circ} \mathrm{C}$, while an average pore size of $7.8 \mathrm{~nm}$ was measured in the raw kaolinite. The thermal activation is the most commonly used physical method to remove the water molecules in the clay particles. These results revealed that the calcination led to the increase of the surface area and the porosity due to bond water release and dehydroxylation occurring. However, an additional step of thermal activation resulted in removing the adsorbed and hydrated water, and volatile organic compounds. This mechanism creates new pores and provides more adsorption sites facilitating higher adsorption of dyes on the NTK particles. The phase analysis of the NTK particles prepared at $300-600{ }^{\circ} \mathrm{C}$ was studied by XRD. The anatase phase and rutile phase $\mathrm{TiO}_{2}$ show different XRD patterns. The peak at the $2 \theta$ of 25.3 is the characteristic peak for the anatase phase (101) $\mathrm{TiO}_{2}$, while 27.3 is the characteristic peak for rutile phase (110) $\mathrm{TiO}_{2}$. The XRD patterns of the NTK particles prepared at different temperatures are shown in Fig 3(I), which shows that calcination temperature plays a significant role in the formation of the $\mathrm{TiO}_{2}$ crystal structures, where the NTK particles have a mixed anatase and rutile $\mathrm{TiO}_{2}$ at the calcination temperature above $500{ }^{\circ} \mathrm{C}$, and only anatase $\mathrm{TiO}_{2}$ is found in the NTK particles calcinated at $300-400{ }^{\circ} \mathrm{C}$. The peaks in the NTK300 and NTK400 particles can be ascribed to the (101), (004), (200), (105), (211) and (118) planes of anatase $\mathrm{TiO}_{2}$ (JCPDS card No. 841286). The anatase phase peaks, such as the (101), (004) and (200) planes decrease significantly as the temperature increases from $300{ }^{\circ} \mathrm{C}$ to $600{ }^{\circ} \mathrm{C}$. At the same time, rutile phase peaks for the NTK500 and NTK600 are related to the (110), (101), (111), (210), and (211) planes (JCPDS card No. 84-1286). Previous studies reported that the anatase $\mathrm{TiO}_{2}$ performed a more prominent photoactivity than the rutile $\mathrm{TiO}_{2}$ due to its lower band energy $[2,5,16,17]$. The $\mathrm{XRD}$ results show that calcination process at a low temperature range of 300-400 ${ }^{\circ} \mathrm{C}$ is more favourable to obtain anatase $\mathrm{TiO}_{2}$. Beyond $400{ }^{\circ} \mathrm{C}$, the diffraction peaks 
of rutile phase become stronger and the intensity of diffraction peaks of anatase phases (or the ratio of $I_{A} / I_{R}$ ) decreases significantly as the temperature rises. Using the zinc oxide spiking method, the amount of anatase $\mathrm{TiO}_{2}$ formed on kaolinite can be estimated to be approximately 9-10 wt\%. Further verification on the size of anatase $\mathrm{TiO}_{2}$ based on the Scherrer equation is consistent with that obtained from TEM $(\sim 10 \mathrm{~nm})$. It is worthwhile to note that our XRD patterns do not present the Ti-N crystal phase as reported by Wang et al [10]. Other studies also reported the absence of Ti-N crystal peak in the XRD patterns for their N-doped $\mathrm{TiO}_{2}$ particles [7, 8, 18, 19].

\subsection{Chemical Analysis of the NTK Catalysts}

The XPS spectra of the NTK particles were measured to identify detailed surface chemical information as shown in Fig 3(II). P25 was also analysed as a reference. Fig 3(II)a shows that the intensity of the NTK particles decreases as increasing calcination temperatures. Fig 3(II)b shows the $\mathrm{N}$ 1s spectra of the NTK and P25 particles. The $\mathrm{N} 1$ s peak is not found in the XPS profiles for P25 and the NTK catalysts prepared at a temperature higher than $500{ }^{\circ} \mathrm{C}$. Minor nitrogen peaks at around $400 \mathrm{eV}$ are observed for the NTK particles calcinated at $300{ }^{\circ} \mathrm{C}$ and $400{ }^{\circ} \mathrm{C}$. For the $\mathrm{N}$ 1s, the high binding energy of around $406 \mathrm{eV}$ can be assigned to nitrogen species bound to various surface oxygen sites ( $\mathrm{NO}$ or $\mathrm{NO}_{2}$ molecules) [20]. The $\mathrm{N}$ 1s peak at 399-400 eV can be attributed to the nitrogen in the form of Ti-N-O linkage [21]. The low $\mathrm{N} 1 s$ bonding energy peak located at $396-397 \mathrm{eV}$ is known as the $\mathrm{N}$ atom replacing the oxygen atoms in the $\mathrm{TiO}_{2}$ crystal lattice to form an N-Ti-N bond [20, 22]. Asahi et al. reported three $\mathrm{N} 1$ s peaks with binding energies of $402 \mathrm{eV}, 400 \mathrm{eV}$ and $396 \mathrm{eV}$ and assigned them as molecularly chemisorbed $\gamma-\mathrm{N}_{2}(\mathrm{BE} \sim 402 \mathrm{eV}$ and $400 \mathrm{eV})$ and atomic $\beta$-N (BE 396 $\mathrm{eV)}$ [23]. Our results show the presence of $\mathrm{N}$ 1s on anatase titanium dioxide prepared at a temperature lower that $400{ }^{\circ} \mathrm{C}$. The disappearance of $\mathrm{N}$ 1s peaks in the NTK prepared at $500{ }^{\circ} \mathrm{C}$ and/or above may be due to merging of doped nitrogen atoms into nitrogen molecules. 
It shows negligible Ti-N formation, which agrees well with our XRD data. These results reveal that the $\mathrm{N}$ might be molecularly chemisorbed on the surface of $\mathrm{TiO}_{2}$. Fig 3(II)c describes the Ti $2 p$ XPS spectra the NTK and P25 catalysts. The spin-orbit components (Ti $2 p_{3 / 2}$ and Ti $2 p_{1 / 2}$ ) of Ti $2 p$ peaks are located at the binding energies of $457.8-458.5 \mathrm{eV}$ for NTK300, NTK400 and NTK500, and $458 \mathrm{eV}$ for P25. The peaks around $458 \mathrm{eV}$ are assigned to Ti $2 p_{3 / 2}[16,17]$. Both NTK300 and NTK400 particles demonstrate the red shift energy of around $1.2 \mathrm{eV}$ comparing with that of NTK500. If that is compared with P25, the red shift is about $0.6 \mathrm{eV}$. The above red shifts appear to be comparable with those determined from computational prediction modelling by Di Valentin et al.[27], who reported a predicted reduction of $0.73 \mathrm{eV}$ for interstitial nitrogen. The XPS result suggests that $\mathrm{Ti}^{3+}$ might exist in NTK300 and NTK400 [18, 22]. Nonetheless, the most important implication is the reduction of the required energy associated with the red shift, resulting in visible light activity for the photo-responsive NTK catalysts.

The photo-oxidation activity of the $\mathrm{N}$-doped $\mathrm{TiO}_{2}$ in visible light region is likely to be an open subject. Asahi et al. proposed that nitrogen atoms were doped into the substitutional sites of $\mathrm{TiO}_{2}$, resulting in visible light response [23]. Previous studies reported that oxygen vacancies enhanced visible light photo-response and the doped nitrogen acted as a blocker for reoxidation of oxygen vacancies $[3,12]$. A few of other studies proposed that the visible light response on $\mathrm{N}$-doped $\mathrm{TiO}_{2}$ arises from electronic transitions from localized states to conduction band [19, 21]. The general accepted theory on how $\mathrm{N}$-doped $\mathrm{TiO}_{2}$ works is the introduction of institutional or substitutional $\mathrm{N}$ in $\mathrm{TiO}_{2}$ crystal lattice structure, which gives rise to the localized states in band gaps and results in reducing the energy required for the interfacial photo-oxidation reaction of the catalyst [21, 22]. The $\mathrm{N}$-doping leads to narrowing of $\mathrm{TiO}_{2}$ band gap via mixing $\mathrm{N} 2 p$ orbital and $\mathrm{O} 2 p$ orbital, and hence visible light-stimulated photocatalytic activity. $\mathrm{N}$-doped anatase $\mathrm{TiO}_{2}$ contains thermally stable single $\mathrm{N}$-atom either 
as a charged diamagnetic N-b centre or as a neutral paramagnetic N-b centre [17]. The Natoms can occupy either interstitial or substitutional positions in $\mathrm{TiO}_{2}$ crystalline [23, 24]. Di Valentin et al. reported a computational calculation of electronic structure using the PBE density function for both substitutional and interstitial $\mathrm{N}$ atoms of intra band gap system, in which occupied $\mathrm{N} 2 p$ localized states appeared approximately $0.14 \mathrm{eV}$ above the valence band edge, compared to the NO bond localized states $(\sim 0.73 \mathrm{eV})[27]$.

EDX scan was performed over the NTK specimen (Fig 2d) to identify the existence of N, and the signal of copper is selected as the reference to eliminate background noise. The data clearly indicate the presence of nitrogen and titanium on kaolinite layered structure resulting from $\mathrm{N}$ doping. Varley and co-workers studied mechanism of visible light photocatalysis in $\mathrm{N}$-doped $\mathrm{TiO}_{2}$ [3]. They discovered that interstitial $\mathrm{N}$ forms a strong bond with $\mathrm{O}$ atom in the $\mathrm{TiO}_{2}$ lattice so that $\mathrm{N}$ shares the same site with an $\mathrm{O}$ atom in the relaxed configuration, leading to the split-interstitial (NO) $)_{0}$ configuration. They also found that interstitial $\mathrm{N}$ can form a complex with $\mathrm{N}$ in the form of a $\left(\mathrm{N}_{2}\right)_{0}$ split interstitial. Our results support the key conclusions from Varley and co-workers, i.e. nitrogen prefers to occupy the oxygen site in ntype $\mathrm{TiO}_{2}$, as proposed to interstitial sites such as $(\mathrm{NO})_{0}$ or $\left(\mathrm{N}_{2}\right)_{0}$, and nitrogen behaves similarly in rutile and anatase.

FTIR studies assist the identification of the minerals present in the NTK catalysts. The coupled vibrations are appreciable due to the availability of various constituents. To recognize mineral species and identify characteristic bands of the NTK, the FTIR spectra were performed in the range from $4000-400 \mathrm{~cm}^{-1}$ to investigate the effect of calcination temperature on the chemical composition of the NTK. We examined the FTIR spectra of the NTK300, NTK400 and NTK500 particles synthesised at 300, 400 and $500{ }^{\circ} \mathrm{C}$, respectively. All the samples present similar spectra. The bands which maxima at 3691, 3651, 3619 and $910 \mathrm{~cm}^{-1}$ correspond to the vibration of inner and outer structural hydroxyl groups in $\mathrm{Al}-\mathrm{OH}$, 
bands at 1113, 1006 and $460 \mathrm{~cm}^{-1}$ belong to Si-O vibrations. The disappearance of the high region bands of $3700-3500 \mathrm{~cm}^{-1}$ could evidence the transformation of kaolinite to metakaolinite during the course of NTK preparation. A strong band located approximately $700 \mathrm{~cm}^{-1}$ attributed to Ti-O stretching and Ti-O-Ti bridging stretching [19]. The co-existence of 1080 and $780 \mathrm{~cm}^{-1}$ peaks corresponding to kaolinites and $660 \mathrm{~cm}^{-1}$ peak for the stretching of O-Ti-O indicates the successful synthesis of titania impregnated kaolinite. The peaks at $1450 \mathrm{~cm}^{-1}$ and $1230 \mathrm{~cm}^{-1}$ can be assigned to the embedded nitrogen in the $\mathrm{TiO}_{2}$ lattice network. However, the peak for Ti-N at $730 \mathrm{~cm}^{-1}$ is not evident. These results further indicate that there is no nitrogen substitutional atom in the $\mathrm{TiO}_{2}$ lattice structure. From our results, we could conclude that the doped nitrogen atoms in our synthesized NTK particles are mainly interstitial.

\subsection{Photocatalytic Activity of the NTK Catalysts}

The photocatalytic activities of the NTK catalysts calcinated at $300-500{ }^{\circ} \mathrm{C}$, and the $\mathrm{TiO}_{2}-\mathrm{K}$ and P25 were examined from UV to visible light range. NTK particles performed a strong absorption of $86-98 \%$ over the wavelength range of $300-500 \mathrm{~nm}$, while the $\mathrm{TiO}_{2}-\mathrm{K}$ and $\mathrm{P} 25$ only showed a high absorption of $85-90 \%$ in the UV region of $350-380 \mathrm{~nm}$, but very low or no visible light absorbance. Under a visible light irradiation, the general absorbance follows an order of NTK300 $>$ NTK400 $>$ NTK500 $>\mathrm{TiO}_{2}-\mathrm{K}>\mathrm{P} 25$. The experimental data of the NTK-photocatalysed reactions show a clear red-shift comparing with $\mathrm{TiO}_{2}-\mathrm{K}$ or P25. The red-shift should be associated with the $N$-doping in intrinsic band gap of $\mathrm{TiO}_{2}$ and the interaction between $N 2 p$ and $O 2 p$ orbitals. The broader absorption peaks are identified to be related to the sub-band gap states of the NTK due to its unique nanostructure. Using the NTK catalysts, we note that the absorbance order of NTK300 $>$ NTK400 $>$ NTK500 is associated with the phase transformation from anatase to rutile as evidenced from XRD analysis. Furthermore, the optical properties of the NTK catalysts are also subjected to the 
amount of nitrogen doped. XPS data imply that more $\mathrm{N}$ atoms are presented in the NTK particles calcinated at low temperatures. Qiu et al reported that the photocatalytic activities of the N-doped $\mathrm{TiO}_{2}$ catalysts appeared to be dependant of the nitrogen doping [4]. The introduction of more $\mathrm{N}$ dopants into $\mathrm{TiO}_{2}$ nanoparticles can be beneficial for improving efficiency and activity of the photocatalytic oxidation. The NTK catalysts perform a broad photo-responsiveness which can be influenced by $\mathrm{N}$-doping amount and $\mathrm{TiO}_{2}$ crystal phases or the $I_{R} / I_{A}$ ratio.

To evaluate the photocatalytic oxidation capability of the NTK catalysts for the degradation of organic contaminant in wastewater, Congo Red was selected as a model surrogate indicator to simulate toxic organic pollutants in industrial wastewater. Congo red is a secondary diazo recalcitrant dye, and causes immense technical difficulty in biological wastewater treatment process $[9,28,29]$. Fig 4(I) presents the profiles of the UV-vis light absorption spectra of CR solution in the presence of NTK300. Before visible light irradiation (time $=0$ ), two absorption peaks of Congo Red are found at $340 \mathrm{~nm}$ and $499 \mathrm{~nm}$, where 499 $\mathrm{nm}$ is directly associated with it conjugate structure. After $1 \mathrm{~h}$ visible light irradiation, obvious decrease in the absorbance is observed for both peaks. The maximum absorption wavelengths are found to have a slight blue shift to 320 and $496 \mathrm{~nm}$. The absorption at both wavelengths steadily reduces after $2 \mathrm{~h}$ irradiation, while the absorbance reduction at $496 \mathrm{~nm}$ appears to be more significant. The $496 \mathrm{~nm}$ peak approaches to zero after $4 \mathrm{~h}$, indicating all CR molecules have been degraded in association with the NTK photocatalysis. On the other hand, the absorbance reduction for the $320 \mathrm{~nm}$ peak seems rather slower. Considering the significant blue shift, the absorbance between $250 \mathrm{~nm}$ and $350 \mathrm{~nm}$ becomes less than 0.1 after $6 \mathrm{~h}$ irradiation. 
Ma et al.[28] and Chong et al.[14] reported that photo-catalytic oxidation using $\mathrm{TiO}_{2}$ can break the azo-bonds and relevant conjugate structures of Congo Red, resulting in the decolourisation of the dye. The CR degradation by the NTK is evident from the disappearance of the $496 \mathrm{~nm}$ peak and CR decolourisation after $2 \mathrm{~h}$ irradiation. The degraded products of naphthalene based segments or diaminobiphenyl moieties are evident from the existence of absorption at 250 to $300 \mathrm{~nm}$. The diminishing absorbance in the UV range at longer reaction time could be attributed to the destruction of aromatic by-products [30]. It is important to note that the NTK has the capability to fully decompose Congo Red under visible light irradiation, as evidenced from the effective CR degradation and aromatic segments at 496 and $300 \mathrm{~nm}$.

\subsection{Photocatalytic Degradation Kinetics using the NTK Catalysts}

Comparison study on the time-dependent CR degradation using the NTK catalysts is able to provide insight to the kinetics of the photo-degradation reaction. The CR photo-degradation at 300 and $496 \mathrm{~nm}$ using the NTK300 was evaluated in the ASP system. $\mathrm{TiO}_{2}-\mathrm{K}$ catalyst and kaolinite particles were also tested under the same reaction conditions as the references. Before visible light irradiation, the suspensions of catalytic particles and CR were vigorously stirred in dark for 30 min to ensure that equilibrium adsorption was acheived. The kinetic profiles of the CR degradation catalysed by $\mathrm{NTK}$ or $\mathrm{TiO}_{2}-\mathrm{K}$ under visible light irradiation are shown in Fig 4(II). No absorbance change over time is found in the control trial using light irradiation only, indicating that CR is relatively stable under visible light irradiation. Slight dye reduction can be observed in the control trials using kaolinite and $\mathrm{TiO}_{2}-\mathrm{K}$ particles at 300 $\mathrm{nm}$ and $496 \mathrm{~nm}$. This reduction is mainly attributed to the physical adsorption of Congo Red by these nanostructured kaolinite particles. Due to the presence of small proportion ( $\sim 4)$ of $\mathrm{UV}$ in visible light region, minor photo-degradation catalysed by the $\mathrm{TiO}_{2}-\mathrm{K}$ is observed. NTK300 demonstrates highly comparable photo-catalytic ability under visible light as 
evidenced from a high percentage of CR disappearance with time. Under $2 \mathrm{~h}$ irradiation, approximate $80 \%$ of CR was degraded, resulting in producing about $30 \%$ intermediate products, including 4-methyly-benzaldehyde, 5-amino-2-methoxyphenol, 4-nitro-1,1biphenly were measured in the solution $[14,26]$. Nonetheless, low degradation rates are observed after 3 h irradiation. Finally, $99 \%$ of CR can be degraded and only $7 \%$ by-products remained in water after at $6 \mathrm{~h}$ irradiation. NTK is able to deliver approximately 2-5 times higher oxidation efficiency on the $\mathrm{CR}$ degradation than that of $\mathrm{TiO}_{2}-\mathrm{K}$ catalyst and 5-10 times higher than that of P25 under the same photo-reaction conditions. The superior interfacial photo-oxidation ability of the NTK under visible light irradiation is attributed by the doped nitrogen and its unique porous-layered structures. The doped nitrogen is able to alter the localised states in the band gaps towards red shift, resulting in reducing energy required for photo-oxidation. On the other hand, the chemically modified layered kaolinite is not only a supportive carrier of $\mathrm{N}$-doped $\mathrm{TiO}_{2}$ nanoparticles, but also a porous absorbent. The coordination of kaolinite surface adsorption and visible light accessibility of $\mathrm{N}$-doped $\mathrm{TiO}_{2}$ nanoparticles on kaolinite surface gives rise to higher degradation efficiency and low energy cost for the semiconductor photocatalytic process. Beyond the superior degradation capacity and visible light accessibility, it is worthwhile to mention that the NTK-driven photocatalysis needs much less net $\mathrm{TiO}_{2}$ crystals than P25 used for the CR degradation trials in the ASP system, as the $\mathrm{TiO}_{2}$ crystals are only approximately $10 \mathrm{wt} \%$ of the NTK particles.

The rate expression for a single-component heterogeneous photocatalytic reaction that involves molecule degradation on the surface of a photocatalyst can be described using the saturation kinetic expression proposed by Langmuir-Hinshelwood:

$$
r=-\frac{d C}{d t}=-\frac{k K_{a d s} C}{1+K_{a d s} C}
$$


where $r$ is the rate of photo-oxidation for dye molecules, $k$ is the rate constant, $C$ is the CR concentration, and $K_{a d s}$ is the dynamic Langmuir adsorption constant. The applicability of Equation 2 is based on the following assumptions: (i) reaction system is in dynamic equilibrium; (ii) the reaction is surface mediated and (3) the competition for the active surface sites by the intermediates and other reactive oxygen species such as $\mathrm{O}_{2}$ is not limiting. If all the assumptions are satisfied, the entire batch ASP system only consists of surface adsorption sites, dye molecules and its intermediates, electron-hole pairs and reactive oxygen species (i.e. $\mathrm{O}_{2}, \mathrm{O}_{2}{ }^{--}$). The rate constant, $k$, is interpreted as the intrinsic reaction rate constant, which includes the rate of $\mathrm{OH}^{\cdot}$ and $\mathrm{O}_{2}{ }^{--}$generation, a function of the absorbed photon flux $I_{a b s}$ $\left[\mathrm{O}_{2}\right]_{a d s}$, competition from intermediate products, and mass transport effects. The second term in Equation 2 is the Langmuir saturation term $\left(K_{a d s} C /\left(1+K_{a d s} C\right)\right)$ represents the fraction of surface sites occupied by dye molecules. The implicit solution for Equation 2 can be rearranged to Equation 3, which can be solved explicitly for $t$ using the discrete change in dye concentrations $C$ from initial concentration $C_{0}$ to a zero point of reference.

$$
\ln \left(\frac{C}{C_{0}}\right)+K_{a d s}\left(C-C_{0}\right)=-k K_{a d s} t
$$

Equation 3 is applied to yield the exact solution for photo-oxidation of dyes on the adsorbed surface, where the rate constant $k$ and Langmuir adsorption constant $K_{a d s}$ can be determined from the reciprocal plot of degradation rate against initial dye concentration. Fig 5 presents the kinetic profiles of CR degradation using NTK, $\mathrm{TiO}_{2}-\mathrm{K}$ and P25 catalysts under $1 \mathrm{~h}$ visible light irradiation. All NTK catalysts demonstrated increasing degradation profiles against irradiation time. For the $\mathrm{TiO}_{2}-\mathrm{K}$ and $\mathrm{P} 25$ systems, only a slight $\mathrm{CR}$ reduction was observed due to their non-sensitivity to visible light irradiation. While both $\mathrm{TiO}_{2}-\mathrm{K}$ and $\mathrm{P} 25$ showed a very low profile for $\mathrm{CR}$ reduction, we note that the $\mathrm{TiO}_{2}-\mathrm{K}$ showed a slightly higher $\mathrm{CR}$ 
removal ability than $\mathrm{P} 25$. This can be attributed by dye adsorption on the $\mathrm{TiO}_{2}-\mathrm{K}$ particles $[14,26]$.

The CR photo-degradation using the NTK catalysts obeys the first-order reaction kinetics. Table 1 presents the first order Langmuir-Hinshelwood degradation expressions and the kinetic data for the CR degradation using various NTK catalysts. From the linear regression, the $k$ varies in a range of $0.0116-0.4019$ mol. $\mathrm{L}^{-1} \mathrm{~min}^{-1}$ and the $K_{a d s}$ is estimated as 0.4066 $0.1580 \mathrm{~min}^{-1}$ for the NTK catalyzed Congo Red photo-degradation in the ASP system. Although NTK500 has a little higher dynamic Langmuir adsorption constant, but the rate constant is smaller than that of NTK300 and NTK400. The highest degradation rates under visible light irradiation are given by NTK300 or NTK400, which are attributed to the presence of more anatase phased $\mathrm{TiO}_{2}$ in their microstructures.

\subsection{Recovery and Reuse Ability of the NTK Catalysts}

In a large scale semiconductor photocatalytic system, whether the catalyst particles can be recovered and regenerated for reuse in a continuous or semi-continuous process is a key technical and economic concern. Our synthesized NTK particles have a size range of approximately 3 - $5 \mu \mathrm{m}$. We examined feasibility for separation and recovery of the NTK catalysts in a semiconductor ASP system. The ASP system was operated under aeration with pumping compressed air through a gas sparger at a flow rate of $0.25 \mathrm{vvm}$, generating fine air bubbles in the ASP system. These air bubbles can maintain the NTK particles be well suspended in liquid phase and promote their contact with CR molecules. After the completion of the photo-degradation operation, the NTK particles can be easily separated through a simple sedimentation or filtration operation. The particle settling ability is an important property related to separation performance. Based on the Kynch's theory, the settling ability of various particles can be examined by testing their hindered settling velocities. Batch 
settling tests of the NTK300 and commercial P25 particles in $50 \mathrm{~mL}$ deionised water were carried out to compare their settleability, where the suspended particles were allowed to settle under gravitation. The relation between the decline of particle interface level and settling time was recorded, and the interface height measured at different time intervals for each sample was used to plot the catalyst settling curves as shown in Fig 6(I). The settling velocities ( $v$ ) were estimated from the initial slope of the settling curves. As expected, the NTK particles performed much higher settling ability than that of P25 due to their large particle sizes. The batch settling velocities are significantly influenced by the amounts of NTK particles in the suspensions. With increasing particle loading, the settling velocity reduces. This is attributed to the rise of overall upward fluid flux when the settling particles displace water in the sediment zone [31]. The particle terminal velocity $\left(v_{t}\right)$ can be simply calculated using Equation 4, where $c$ is the volume fraction of the particles.

$$
v=v_{t}(1-c)
$$

Since the instantaneous concentrations at the interface of different zones are not constant, the settling velocity is dependent on the interface height, settling time and particle loading as expressed by Richardson and Zaki relation, Equation 5.

$$
\log \left(v_{t}\right)=\log \left(v_{t 0}\right)+(N) \log (1-c)
$$

The single particle terminal velocity $\left(v_{t 0}\right)$ can be estimated by plotting $\log v_{t}$ against $\log (1-c)$, and the $v_{t 0}$ is found to be $6.36 \times 10^{-3} \mathrm{~m} \mathrm{~s}^{-1}$, which is similar as the $5.28 \times 10^{-3} \mathrm{~m} \mathrm{~s}^{-1}$ for the $\mathrm{TiO}_{2^{-}}$ K[31]. We repeated this batch settling tests on the regenerated NTK particles after each thermal regeneration cycle, and found that the regeneration process slightly affects the settling ability of NTK particles in suspensions. Obviously, NTK particles can facilitate post sedimentation separation process. The high settling ability of the NTK particles makes them technically promising in a slurry sequential batch reactor system for water treatment. All 
NTK particles can been recovered for reuse by either micro-filtration using $2 \mu \mathrm{m}$ filters or centrifugation at $1000 \mathrm{rpm}$ for $5 \mathrm{~min}$.

In order to determine the photo-degradation capability during repetitive use of the NTK photocatalysts, we operated our ASP system in a semi-continuous mode. CR solution (20 ppm) with NTK catalytic particles $\left(1 \mathrm{~g} \mathrm{dm}^{-3}\right)$ were aerated at $0.25 \mathrm{vvm}$ for $2 \mathrm{~h}$ under visible light irradiation and then the slurry liquid was settled for $0.5 \mathrm{~h}$ to remove the supernatant in the ASP. The remained NTK particles were reused in the following photo-degradation trials. Fig 6(II) presents the NTK-catalysed degradation profiles in the semi-continuous process. The results clearly indicate no apparent deactivation of the NTK catalysts. Photo-degradation rates $(r)$ for each cycle remain at approximately $90-93 \%$ of total degradation capability within 6 trials of the semi-continuous operations. The slight reduction in CR degradation after each recycling trial was attributed to the fact that very small amount of NTK particles might be remained in the supernatant. The NTK photocatalysts demonstrate excellent catalytic stability and settling ability in the heterogeneous visible-light-driven photocatalytic system to effectively decompose organic pollutants in water, which makes them potential application in water or wastewater treatment.

\section{Conclusion}

In this study, a novel visible light active photocatalyst of nitrogen-doped $\mathrm{TiO}_{2}$ hybridized with kaolinite was synthesised by combining the mineral impregnation and $\mathrm{N}$-doping methods. Morphological information indicates the nano-sized $\mathrm{N}$-doped $\mathrm{TiO}_{2}$ particles have been hybridized into layered kaolinite. Characterisation from XPS, XRD and FTIR reveals that the doped nitrogen in NTK particles inclines toward interstitial. The resulting NTK exhibits superior capacity on the photo-degradation of organic compound under visible light irradiation by the coordination of kaolinite surface absorption and the $\mathrm{N}$-doped $\mathrm{TiO}_{2}$ 
degradation on kaolinite surface. We could claim that the porous and multiple-layered structure of the kaolinite particles give rise to the special properties to stabilize nitrogen doping and $\mathrm{TiO}_{2}$ immobilization, but also to enhance photocatalytic performance. Importantly, the $\mathrm{N}$-doped $\mathrm{TiO}_{2}$ photo-catalysts can be easily recovered in a downstream process for reuse. These advantages of high catalytic ability, visible light accessibility and excellent recoverability make the NTK catalysts promising for the development of a cost-effective and energy saving technology for the industrial water and wastewater treatment.

\section{Acknowledgement}

The work was supported by the BioNanotechnology Laboratory: Energy, Water and Materials at the University of Adelaide, Adelaide, Australia.

\section{References}

[1]. M.N. Chong, B. Jin, C.W. Chow, C. Saint, Recent development in photocatalytic water treatment technology: A review. Water Res. 44, (2010) 2997-3027.

[2]. H. Fakhouri, J. Pulpytel, W. Smith, A. Zolfaghari, H. Mortaheb, H. Meshkini, R. Jafari, Sutter, F. Arefi-Khonsari, Control of the visible light water splitting and photocatalysis of nitrogen doped $\mathrm{TiO}_{2}$ thin films deposited by reactive magnetron sputtering. Appl. Catal. B-Environ. 144, (2014) 12-21.

[3]. J. Varley, A. Janotti, C. van de Walle, Mechanisms of civible-light photocatalysis in nitrogen- doped $\mathrm{TiO}_{2}$, Adv. Mater. 23, (2011) 2343-2347.

[4]. X. Qiu, Y. Zhao, C. Burda, Synthesis and characterization of nitrogen-doped IVB visibleLight-photoactive metal oxide nanoparticles, Adv. Mater. 19, (2007) 3995-3999.

[5]. H. Tong, S. Ouyang, Y. Bi, N. Umewrzawa, O. Oshikiri, J. Ye, Nano-photocatalytic materils: possibilities and challenges. Adv. Mater. 24, (2012) 229-251. 
[6]. S. Cao, K. L. Yeung, P. L. Yue, Preparation of freestanding and crack-free titania-silica aerogels and their performance for gas phase, photocatalytic oxidation of VOCs, Applied Catalysis B: Environmental, 68 (3-4), (2006), 99-108.

[7]. X. Chen, L. Liu, P.Y. Yu, S.S. Mao, Increasing solar absorption for photocatalysis with black hydrogenated titanium dioxide nanocrystals, Science, 331, (2011) 746-750.

[8]. M.M. Khan, A. Sajid, D. Ansari, M. Pradhan, O. Ansari, D.H. Han, J. Lee. H.C. Cho, Band gap engineered TiO2 nanoparticles for visible light induced photoelectrochemical and photocatalytic studies, J. Mater. Chem. A 2, (2014) 637-644

[9]. M.N. Chong, V. Vimonses, S. Lei, B. Jin, C. Saint, Synthesis and characterisation of novel titania impregnated kaolinite nano-photocatalyst. Micropor Mesopor Mat. 117, (2009) 233-242.

[10]. Y. Wang, C. Feng, M. Zhang, J. Yang, Z. Zhang, Enhanced visible light photocatalytic activity of $\mathrm{N}$-doped $\mathrm{TiO} 2$ in relation to single-electron-trapped oxygen vacancy and doped-nitrogen, Appl Catal B-Environ. 100, (2010) 84-90.

[11]. S. Chen, J. Bi, Y. Zhao, L. Yang, C. Zhang, Y. Ma, Q. Wu, X. Wang, Z. Hu, Nitrogendoped carbon nanocages as efficient metal-free electrocatalysts for oxygen reduction reaction. Adv. Mater., 24, (2012) 5593-5597.

[12]. Y. Liu, J. He, Y. Sun, J. Hu, C. Li, G. Xue, S. Ognier, A comparison of N-doped TiO2 photocatalysts preparation methods and studies on their catalytic activity. J. Chem. Technol. Biotechnol. 88, (2013) 1815-1821.

[13]. Y. T. Lin, C. H. Weng, F. Y. Chen, Key operating parameters affecting photocatalytic activity of visible-light-induced C-doped $\mathrm{TiO} 2$ catalyst for ethylene oxidation, Chemical Engineering Journal, 248, (2014) 175-183.

[14]. M.N. Chong, B. Jin, C.W. Chow, C. Saint, A new approach to optimise an annular slurry photoreactor system for the degradation of Congo Red: Statistical analysis and modelling, Chem. Eng. J. 152; (2009) 158-166. 
[15]. A. Tarasov, G. Trusov, A. Minnekhanov, D. Gil, E. Konstantinova, E. Goodilin, Y. Dobrovolsky, Facile preparation of nitrogen-doped nanostructured titania microspheres by a new method of Thermally Assisted Reactions in Aqueous Sprays, J. Mater. Chem. A, 2, (2014) 3102-3109.

[16]. C. Valentin, E. Finazzi, G Pacchioni, A. Selloni, E. Giamello, N-doped TiO2: Theory and Experiment, Chem. Phys. 339, (2007) 44-56.

[17]. M. Harb, P. Sautet, P. Raybaud, Anionic or Cationic S-Doping in Bulk Anatase TiO2: Insights on Optical Absorption from First Principles Calculations J. Phys. Chem. C, 117, (2013) 8892-8902.

[18]. C. Zhang, F. Fu, N. Liu, Y. Wang, Z. Liu, Synthesis of nitrogen-doped graphene using embedded carbon and nitrogen source. Adv. Mater. 23, (2011) 1020-1204.

[19]. Z. Jiang, L. Kong, S.F. Alenazey, Y. Qian, L. France, X. Tiancun, P. Peter, Edwards Enhanced visible-light-driven photocatalytic activity of mesoporous $\mathrm{TiO}_{2}-\mathrm{xNx}$ derived from the ethylenediamine-based complex, Nanoscale, 5, (2013) 5396-5402

[20]. Z.Y.Hu, L.B.Y, Xu, J.F. Chen, Ordered arrays of N-doped mesoporous titania spheres with high visible light photocatalytic activity. Mater. Lett. 106, (2013) 421-424.

[21]. G. Yang, Z. Jiang, H. Shi, T. Xiao, Z. Yang, Preparation of highly visible-light active N-doped $\mathrm{TiO}_{2}$ photocatalyst. J. Mater. Chem. A. 20, (2010) 5301-5309.

[22]. G. Yang, Z. Jiang, H. Shi, T. Xiao, Z. Yang, Study on the photocatalysis of F-S codoped $\mathrm{TiO}_{2}$ prepared using solvothermal method, Appl. Catal., 96, (2010) 458-465.

[23]. R. Asahi, T. Morikawa, T. Ohwaki, K. Aoki, Visible-light photocatalysis in nitrogen doped titanium oxides. Science, 293, (2001) 269-271.

[24]. M. Harb, P. Sautet, P. Raybaud, Anionic or cationic S-doping in bulk anatase TiO2: insights on optical absorption from first principles calculations. J. Phys. Chem. C . 117, (2013) 8892-8902. 
[25] R. Molinari, C. Lavorato, P. Argurio, Photocatalytic reduction of acetophenone in membrane reactors under $\mathrm{UV}$ and visible light using $\mathrm{TiO} 2$ and $\mathrm{Pd} / \mathrm{TiO} 2$ catalysts, Chemical Engineering Journal, 274, (2015), 307-316

[26] D. Pang, L. Qiu, R. Zhu, F. Ouyang, Silica supported image/TiO2 for photocatalytic decomposition of acrylonitrile under simulant solar light irradiation, Chemical Engineering Journal, 270, (2015) 590-596

[27]. C. Di Valentin, G. Pacchioni, A. Selloni, E. Giamello, Characterization of paramagnetic species in $\mathrm{N}$-doped $\mathrm{TiO}_{2}$ powders by EPR spectroscopy and DFT calculations, J. Phys. Chem. B, 109, (2005) 11414-11422.

[28]. H. Ma, M. Wang, R. Yang, J. Zhao, Z. Shen, S. Yao, Radiation degradation of Congo Red in aqueous solution, Chemosphere, 68, (2007) 1098-1104.

[29]. S. Cao, K. L. Yeung, J. K.C. Kwan, P.M.T. To, S.C.T. Yu, An investigation of the performance of catalytic aerogel filters, Applied Catalysis B: Environmental, 86 (3-4), (2009), 127-136.

[30] R. Homlok, E. Takacs, L. Wojnarovits, Radiolytic degradation of 2,4dichlorophenoxyacetic acid in dilute aqueous solution: pH dependence J. Radioanal Nucl. Chem. 284, (2010) 415-419.

[31]. V. Vimonses, M.N. Chong, B. Jin, Evaluation of the physical properties and photodegradation ability of titania nanocrystalline impregnated onto modified kaolin, Micropor. Mesopor. Mat. 132, (2010) 201-209. 


\section{Figure Captions}

Figure 1 (I) Photo of annular slurry photo-reactor (ASP), and (II) Sketch of a semicontinuous operation mode with three phase cycle: (1) $\mathrm{TiO}_{2}$ /wastewater charge; (2) photocatalytic reaction, and (3) discharge of $2 / 3$ of original and UV reactivation on catalyst.

Figure 2. Morphological analysis of the NTK particles (a) SEM, (b) HRTEM, (c) Low magnification SEM, (d) SEM image with EDX analysis.

Figure 3. (I) XRD patterns for the NTK catalysts prepared at different calcination temperatures, and (II) XPS spectra of $\mathrm{TiO}_{2}$ (P25) and various NTK catalysts prepared at different calcination temperatures: (a) whole XPS spectra, (b) $1 \mathrm{~s}$ spectra of $\mathrm{N}$, and (c) 2p spectra of Ti.

Figure 4. (I) UV-visible absorption spectra of Congo Red in the presence of NTK 300 over 6 hours, and (II) Congo Red photo-degradation profiles in the ASP system using the $\mathrm{NTK300}(\boldsymbol{\bullet}), \mathrm{TiO}_{2}-\mathrm{K}(\boldsymbol{\bullet})$, kaolinite( $\bullet$ ), and visible light(•): (a) Congo Red absorption band at $300 \mathrm{~nm}$ and (b) Congo Red absorption band at $496 \mathrm{~nm}$.

Figure 5. Photo-degradation kinetics profiles of Congo Red using $\mathrm{NTK}, \mathrm{TiO}_{2}-\mathrm{K}$ and $\mathrm{P} 25$ catalysts in the ASP system under visible light irradiation (450-550nm), (catalyst loading: 1g/L, Congo Red concentration $\mathrm{C}_{0}: 20 \mathrm{ppm}$ and aeration rate: $0.5 \mathrm{vvm}$ )

Figure 6. (I) Settling curves of NTK300 and P25 catalysts in $50 \mathrm{ml}$ water, and (II) Photodegradation profiles of Congo Red using the NTK300 catalyst in semi-continuous operation cycles under visible light. (NTK300 catalyst loading 1g/L, Congo Red concentration c0 $20 \mathrm{ppm}$, and aeration rate $0.5 \mathrm{vvm}$ ). 
Figure 1
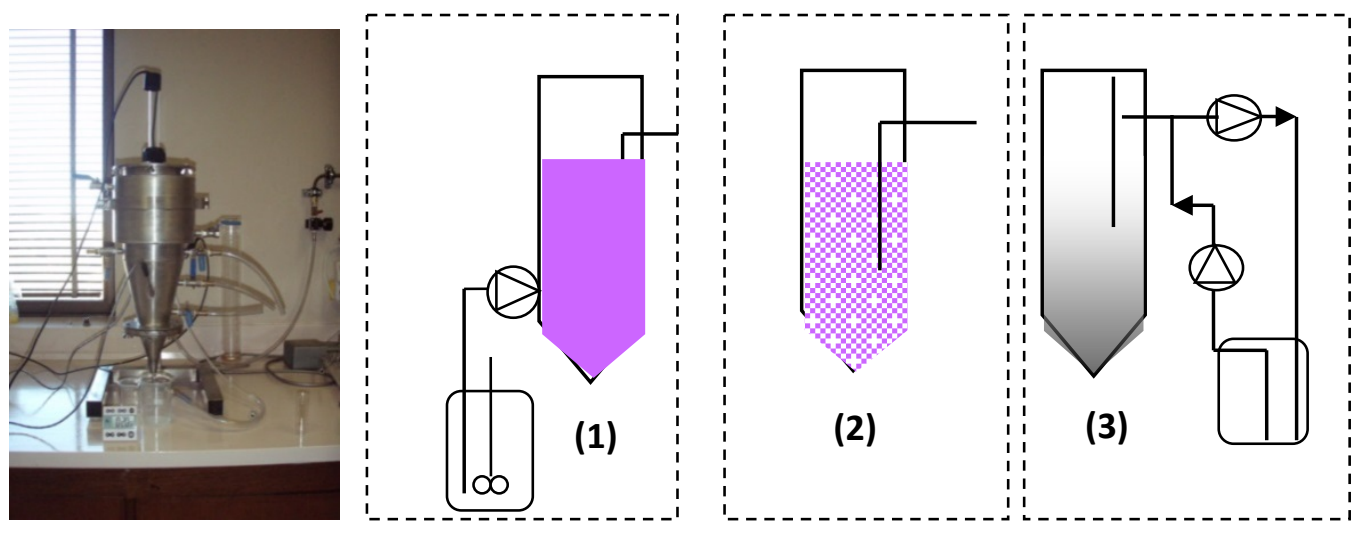

(I)

(II) 
Figure 2

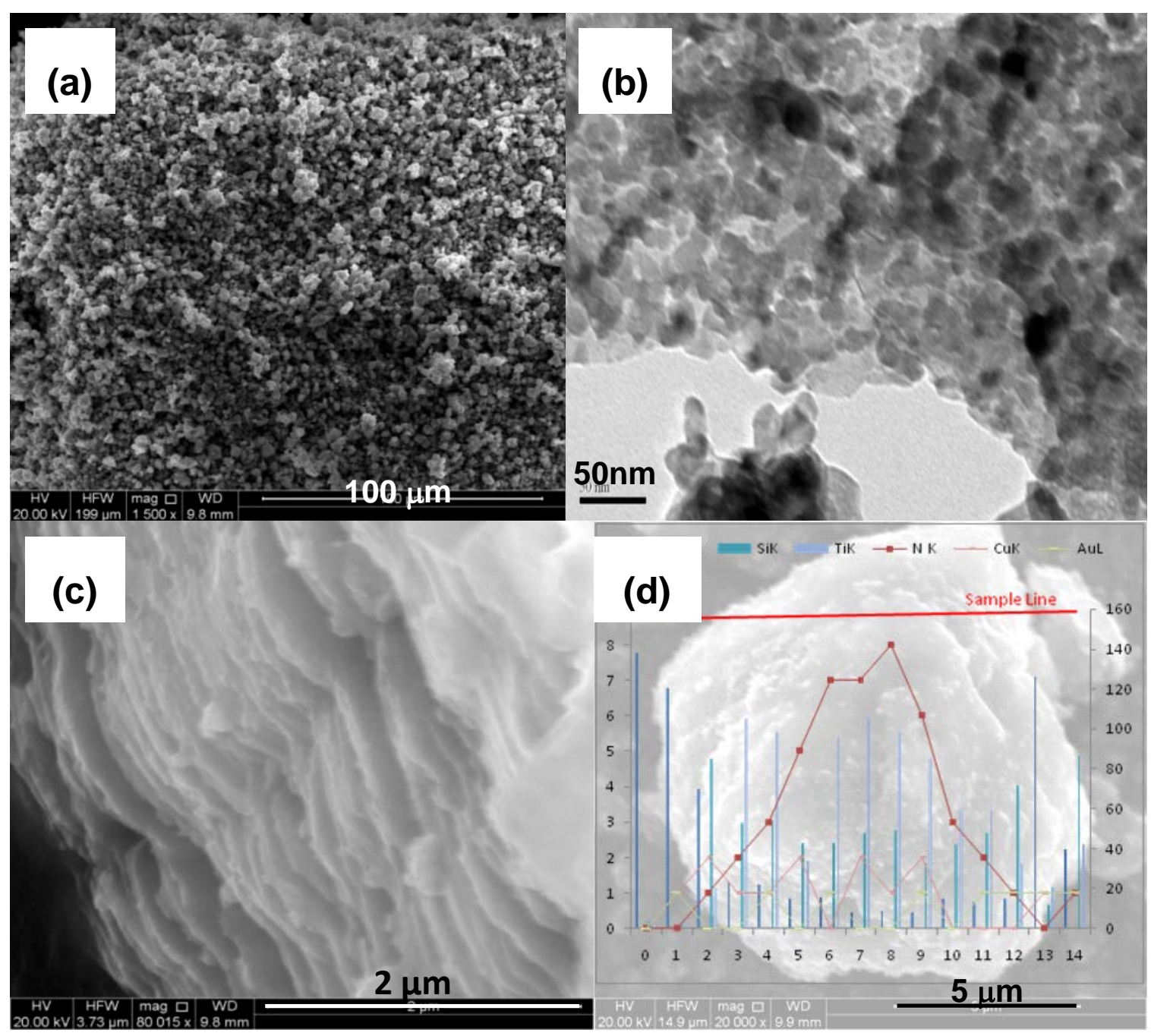


Figure 3
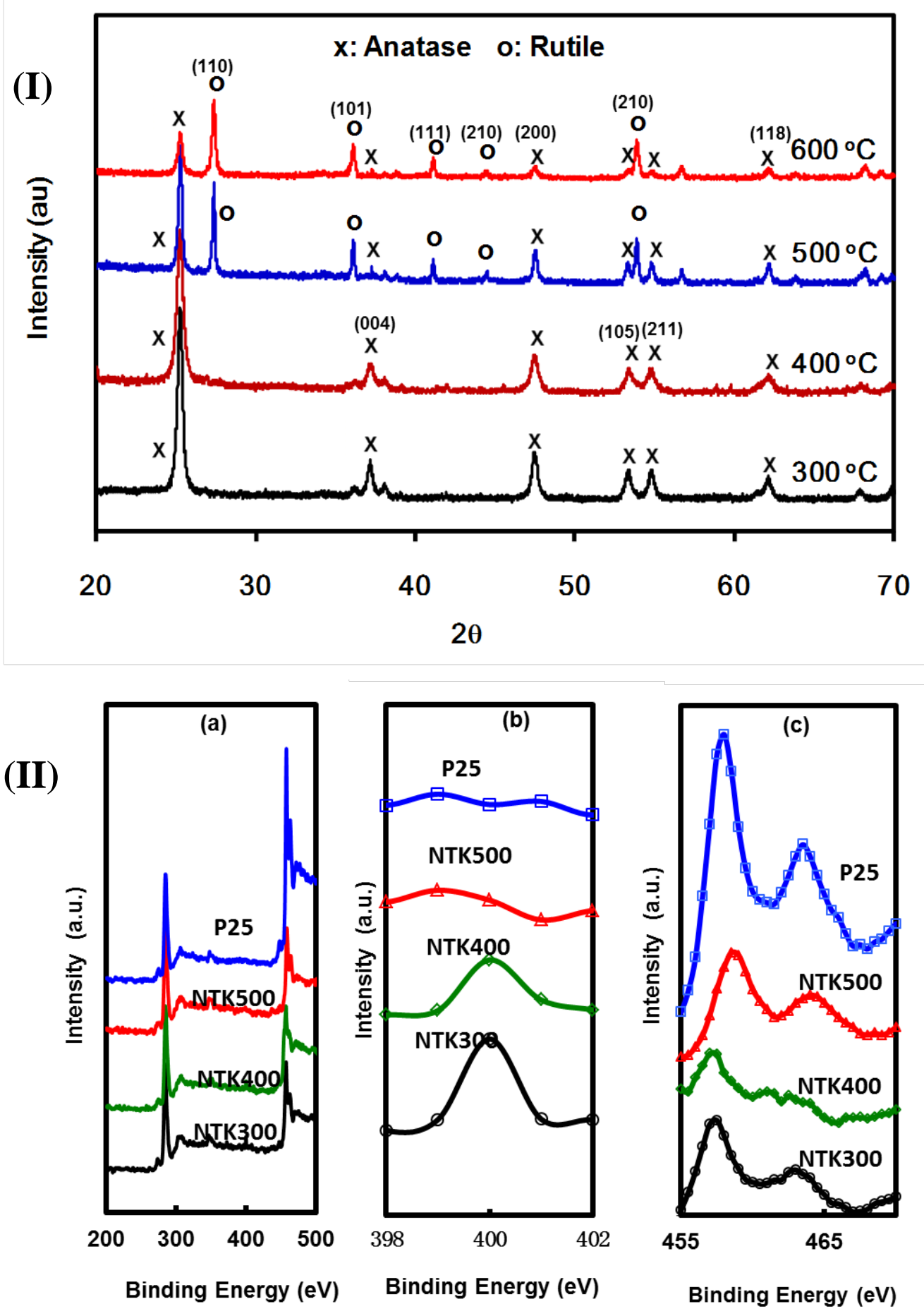
Figure 4
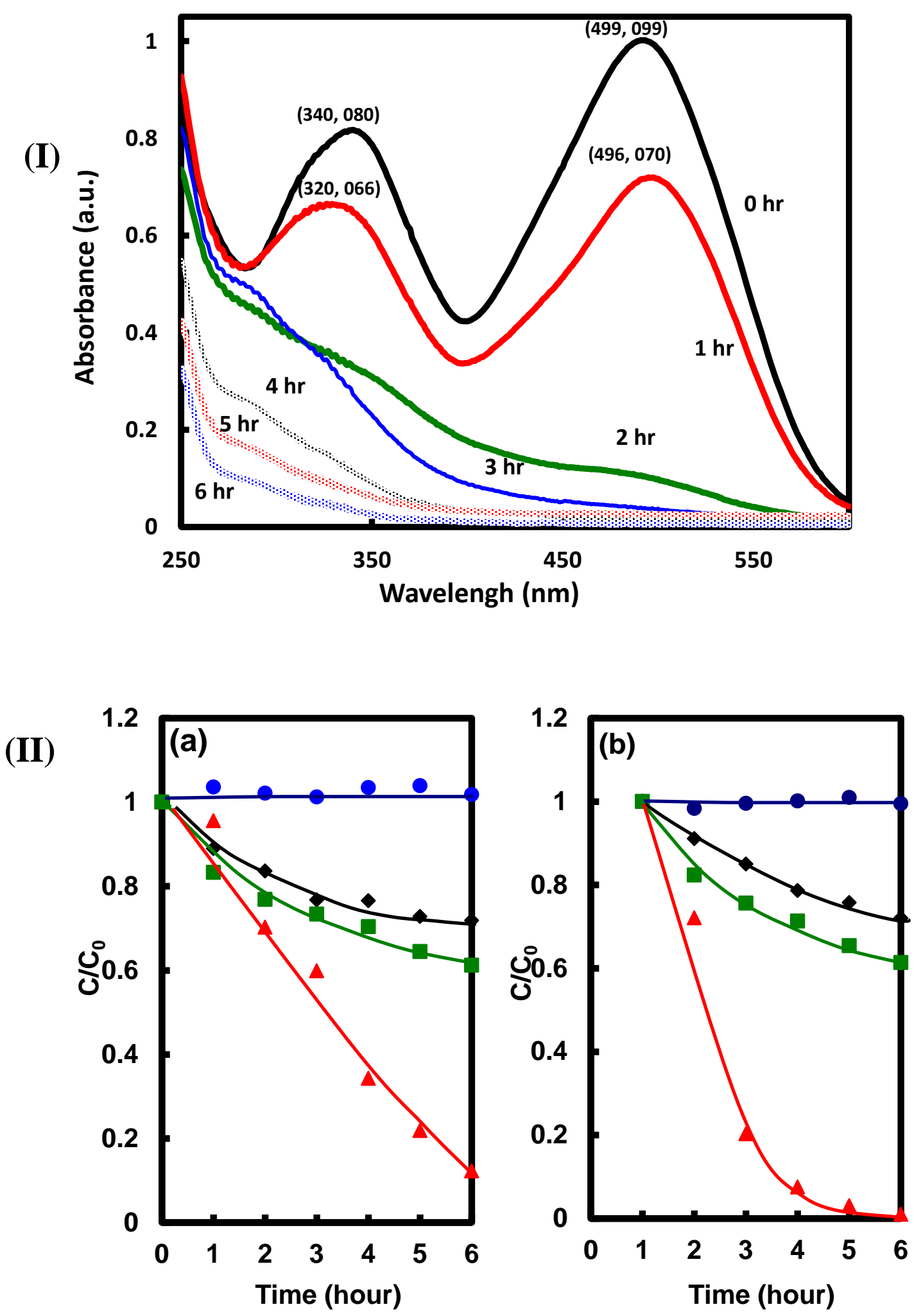
Figure 5

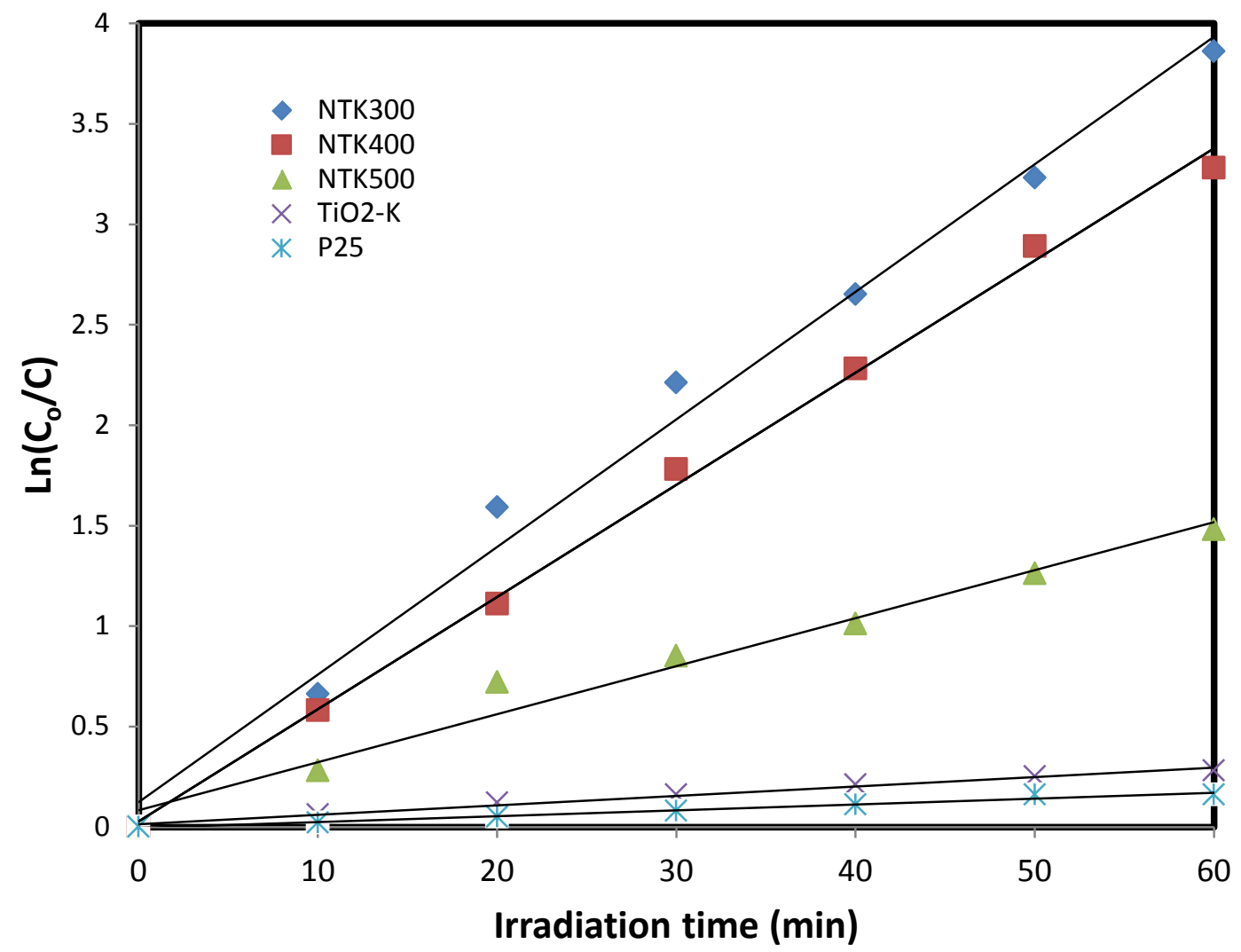


Figure 6
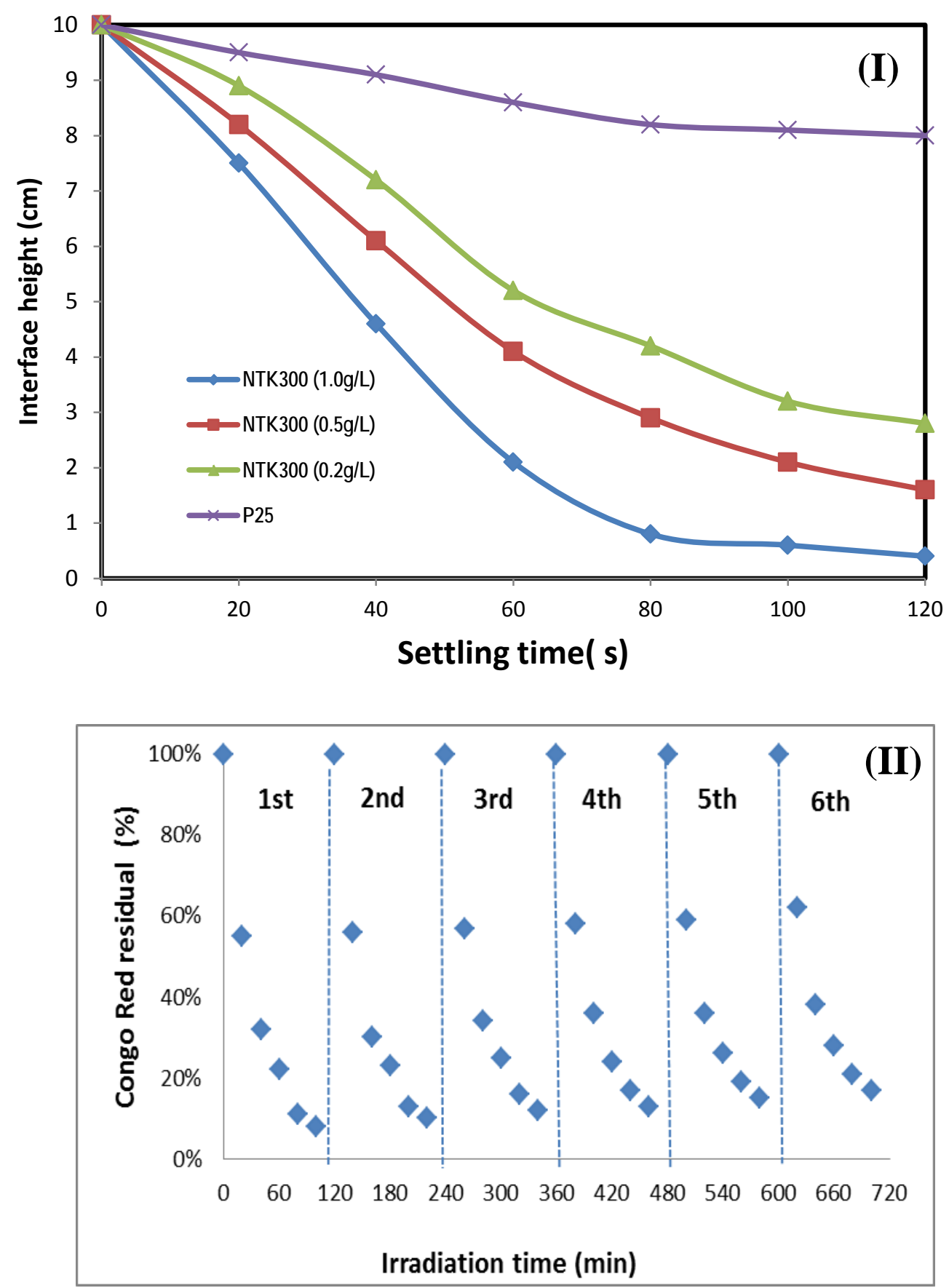
Table 1 Kinetics on the photo-degradation of Congo Red (496 nm absorption) using various NTK catalysts under visible light irradiation.

\begin{tabular}{l|l|l|l|l}
\hline Catalyst & $\begin{array}{l}\text { Langmuir-Hinshelwood } \\
\text { kinetic expression }\end{array}$ & $\begin{array}{l}\text { Langmuir adsorption } \\
\text { constant, } K_{a d s}\left(\mathrm{~min}^{-1}\right)\end{array}$ & $k\left(\mathrm{~mol}^{-1} \mathrm{~L}^{-1} \mathrm{~min}^{-1}\right)$ & coefficient, $\mathrm{R}^{2}$ \\
\hline NTK300 & $\mathrm{y}=0.0635 \mathrm{x}+0.1236$ & 0.1580 & 0.4019 & 0.9906 \\
\hline NTK400 & $\mathrm{y}=0.0558 \mathrm{x}+0.10282$ & 0.1397 & 0.3994 & 0.9974 \\
\hline NTK500 & $\mathrm{y}=0.0047 \mathrm{x}+0.0139$ & 0.4066 & 0.0116 & 0.9890 \\
\hline
\end{tabular}

